\title{
ELECTRONIC PROPERTIES OF MONOCAPPED PRISMANE AND BASKET IRON-SULPHUR CLUSTERS
}

\author{
B. S. SNYDER, M. S. REYNOLDS and R. H. HOLM* \\ Department of Chemistry, Harvard University, Cambridge, MA 02138, U.S.A.
}

and

\section{G. C. PAPAEFTHYMIOU and R. B. FRANKEL $\dagger$}

Francis Bitter National Magnet Laboratory, Massachusetts Institute of Technology, Cambridge, MA 02139, U.S.A.

\begin{abstract}
The ground state electronic properties of the mixed-valence clusters $\mathrm{Fe}_{7} \mathrm{~S}_{6}$ $\left(\mathrm{PEt}_{3}\right)_{4} \mathrm{Cl}_{3}(1), \mathrm{Fe}_{6} \mathrm{~S}_{6}\left(\mathrm{PEt}_{3}\right)_{4} \mathrm{~L}_{2}\left[\mathrm{~L}=\mathrm{Cl}^{-}\right.$(2), $\mathrm{Br}^{-}$(4), I- (5) and $\mathrm{PhS}^{-}$(6)], $\mathrm{Fe}_{6} \mathrm{Se}_{6}$ $\left(\mathrm{PEt}_{3}\right)_{4} \mathrm{Cl}_{2}(3)$ and $\left[\mathrm{Fe}_{6} \mathrm{~S}_{6}(\mathrm{PEt})_{6}\right]^{1-}(9)$, have been investigated by magnetic susceptibility, magnetization and Mössbauer spectroscopic measurements. Cluster 1 has a (idealized $C_{3 v}$ ) monocapped prismane structure and clusters 2-6 and 9 adopt the $C_{2 v}$ "basket" configuration based on the $\left[\mathrm{Fe}_{6}\left(\mu_{2}-\mathrm{S}\right)\left(\mu_{3}-\mathrm{S}\right)_{4}\left(\mu_{4}-\mathrm{S}\right)\right]^{2+, 1+}$ core unit. From magnetic properties, the ground states $S=1 / 2(1,9)$ and $S=1(2-5)$ were established. Unlike the other clusters, 6 did not show a Curie region of susceptibility; its ground state was not directly determined but is probably $S=1$. Mössbauer spectra were successfully analysed in terms of a $1: 1: 1$ iron site population. Isomer shifts and quadrupole splittings were assigned to each site. Magnetically perturbed spectra obtained in applied fields of 60-80 kOe were analysed to give the magnetic hyperfine parameters and magnetic hyperfine fields in clusters 1-5 and 9. The magnetic spectra demonstrate antiferromagnetic spin coupling which affords the indicated ground states.
\end{abstract}

Nearly all iron-sulphur clusters are characterized by core structures that are built up entirely by vertex-sharing and/or edge fusion of $\mathrm{Fe}_{2} \mathrm{~S}_{2}$ rhombs. ${ }^{1.2}$ The prototype single planar rhomb is found in the binuclear species $\left[\mathrm{Fe}_{2} \mathrm{~S}_{2} \mathrm{~L}_{4}\right]^{2-}$. Clusters proceed in complexity from this type to those with nuclearities 3, 4, 6, 7, 8 and $18 .^{2,3}$ Excluding organometallics and with the exception of $\left[\mathrm{Fe}_{6} \mathrm{~S}_{8}\left(\mathrm{PEt}_{3}\right)_{6}\right]^{2+, 1+4,5}$ in the preceding set, these clusters have as terminal ligands, halide, $\mathrm{RS}^{-}$or $\mathrm{RO}^{-}$. The electronic properties of many of these materials have been probed by application of Mössbauer spectroscopy and by magnetization and magnetic susceptibility measure-

* Author to whom correspondence should be addressed. $\dagger$ Present address : Department of Physics, California Polytechnic State University, San Luis Obispo, CA 94307, U.S.A. ments. For example, the ground spin states and associated matters of the electronic structures of cubane-type $\left[\mathrm{Fe}_{4} \mathrm{~S}_{4}(\mathrm{SR})_{4}\right]^{3-, 2-, 1-}$ clusters have been eluciated in some detail by these methods. ${ }^{6-8}$ All of these clusters have the common property of molecular antiferromagnetism.

As part of our work on higher-nuclearity $\mathrm{Fe}-\mathrm{S}$ clusters, we have recently prepared and described the structures and certain reactivity aspects of a new series of hexa- and heptanuclear clusters. ${ }^{3.9-12}$ These differ from the above in having a mixed ligand set that includes tertiary phosphines and core structures not yet found in the absence of phosphine. With reference to Fig. 1, the core geometry of $\mathrm{Fe}_{7} \mathrm{~S}_{6}\left(\mathrm{PEt}_{3}\right)_{4} \mathrm{Cl}_{3}{ }^{9}$ (1) approaches that of a monocapped hexagonal prism, while that of $\mathrm{Fe}_{6}$ $\mathrm{S}_{6}\left(\mathrm{PR}_{3}\right)_{4} \mathrm{~L}_{2}, \mathrm{~L}=$ halide $^{10,11}(2-5,7)$ and thiolate ${ }^{3}$ $(6,8)$, and $\left[\mathrm{Fe}_{6} \mathrm{~S}_{6}\left(\mathrm{PEt}_{3}\right)_{6}\right]^{1+12}(9)$ resembles a basket, with the lower $\mathrm{Fe}-\mathrm{S}-\mathrm{Fe}$ fragment, which 


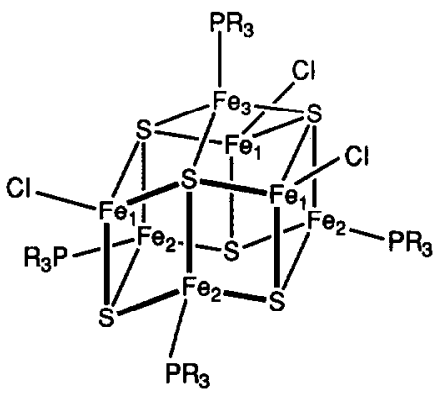

1

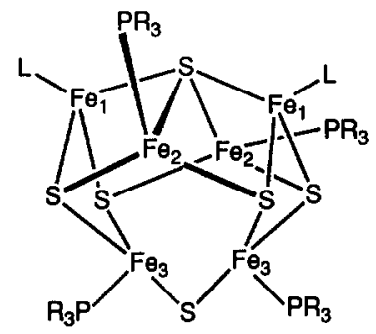

$2-5,7$

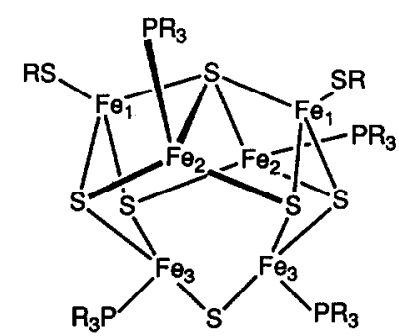

6,8

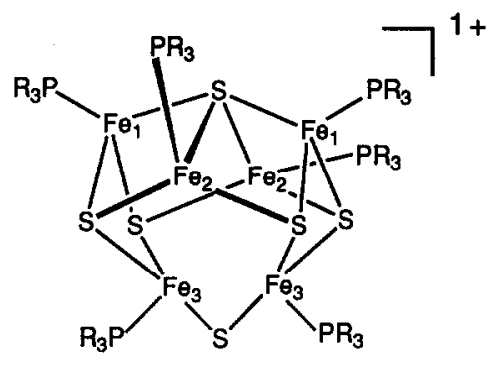

9

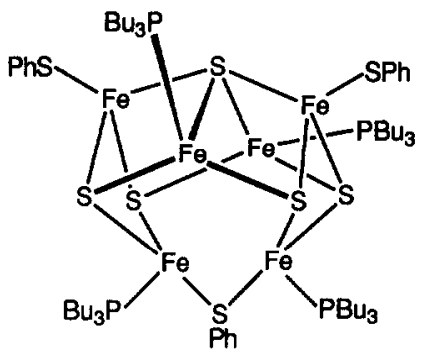

10

Fig. 1. Schematic structures of clusters 1-10 illustrating the monocapped prismane (1) and basket (2-10) topologies. Iron atoms are labelled so as to correspond to the site assignments in Table 2.

is not part of the aforementioned rhomb, serving as the handle. We designate these as "basket" clusters, as a means of distinguishing their $\left[\mathrm{Fe}_{6} \mathrm{~S}_{6}\right]$ core topology from the idealized hexagonal prisms present in the "prismane" clusters, $\left[\mathrm{Fe}_{6} \mathrm{~S}_{6} \mathrm{~L}_{6}\right]^{2-, 3-} .{ }^{13-16} \mathrm{The}$ structures of $\mathrm{Fe}_{6} \mathrm{~S}_{6}\left(\mathrm{PBu}_{3}\right)_{4} \mathrm{Cl}_{2},{ }^{11} \mathrm{Fe}_{6} \mathrm{~S}_{6}\left(\mathrm{PEt}_{3}\right)_{4}(\mathrm{~S}-p$ $\left.\mathrm{C}_{6} \mathrm{H}_{4} \mathrm{Br}\right)_{2}{ }^{3}$ and $\left[\mathrm{Fe}_{6} \mathrm{~S}_{6}(\mathrm{PEt})_{6}\right]^{1+12}$ define the basket topology, which is manifested in virtually isometric $\left[\mathrm{Fe}\left(\mu_{2}-\mathrm{S}\right)\left(\mu_{3}-\mathrm{S}\right)_{4}\left(\mu_{4}-\mathrm{S}\right)\right]^{2+, 1+}$ core units. This unique topology is supported, in part, by the unusual coordination at the $\mathrm{FeS}_{3} \mathrm{P}$ sites. Whereas $\mathrm{FeS}_{3} \mathrm{~L}$ sites in these and numerous other clusters have a distorted tetrahedral configuration, the phosphine-ligated sites exhibit a roughly trigonal pyramidal geometry, with the $\mathrm{Fe}$ atom closely approaching the $\mathrm{S}_{3}$ plane. These species are also among the most reduced $\mathrm{Fe}-\mathrm{S}$ clusters, with $\mathrm{Fe}$ mean oxidation states of +2.14 in $\mathrm{Fe}_{7} \mathrm{~S}_{6}\left(\mathrm{PEt}_{3}\right)_{4} \mathrm{Cl}_{3},+2.17$ in $\left[\mathrm{Fe}_{6} \mathrm{~S}_{6}\right.$ $\left.\left(\mathrm{PEt}_{3}\right)_{6}\right]^{1+}$ and +2.33 in $\mathrm{Fe}_{6} \mathrm{~S}_{6}\left(\mathrm{PEt}_{3}\right)_{4} \mathrm{~L}_{2}$. As a result of their high nuclearities, unusual ligand sets and previously unencountered core structures, these molecules are of current interest as the newest additions to the extensive family of $\mathrm{Fe}-\mathrm{S}$ clusters, which now encompasses seven nuclearities and 10 core structural types. ${ }^{1-3}$ Most of these clusters exist in two or more oxidation levels, some of which have been isolated.
Their unique core structure suggests that the basket clusters may have unusual electronic features. Ground state properties, previously uninvestigated, have been examined by magnetic and Mössbauer techniques, and the leading results are reported here.

\section{EXPERIMENTAL}

\section{Preparation of compounds}

The compounds $\mathrm{Fe}_{7} \mathrm{~S}_{6}\left(\mathrm{PEt}_{3}\right)_{4} \mathrm{Cl}_{3} \quad(\mathbf{1}){ }^{9}{ }^{9} \mathrm{Fe}_{6} \mathrm{~S}_{6}$ $\left(\mathrm{PEt}_{3}\right)_{4} \mathrm{Cl}_{2} \quad$ (2), ${ }^{11} \quad \mathrm{Fe}_{6} \mathrm{Se}_{6}\left(\mathrm{PEt}_{3}\right)_{4} \mathrm{Cl}_{2} \quad$ (3), ${ }^{11} \quad \mathrm{Fe}_{6} \mathrm{~S}_{6}$ $\left(\mathrm{PEt}_{3}\right)_{4} \mathrm{Br}_{2} \quad$ (4), ${ }^{11} \quad \mathrm{Fe}_{6} \mathrm{~S}_{6}\left(\mathrm{PEt}_{3}\right)_{4} \mathrm{I}_{2} \quad(5),{ }^{11} \quad \mathrm{Fe}_{6} \mathrm{~S}_{6}$ $\left(\mathrm{PEt}_{3}\right)_{4}(\mathrm{SPh})_{2} \quad(6),{ }^{3} \quad \mathrm{Fe}_{6} \mathrm{~S}_{6}\left(\mathrm{PEt}_{3}\right)_{4}\left(\mathrm{~S}-p-\mathrm{C}_{6} \mathrm{H}_{4} \mathrm{Br}\right)_{2}$ $(8)^{3}$ and $\left[\mathrm{Fe}_{6} \mathrm{~S}_{6}\left(\mathrm{PEt}_{3}\right)_{6}\right]\left(\mathrm{BF}_{4}\right)(9)^{12}$ were prepared as previously described.

\section{Physical measurements}

All measurements were performed under strict anaerobic conditions. Magnetic susceptibility and magnetization measurements at applied fields of 10 $\mathrm{kOe}$ and up to $50 \mathrm{kOe}$, respectively, were carried out on a SHE 905 SQUID magnetometer operating between 1.8 and $300 \mathrm{~K}$. Solid state measurements were made on finely ground polycrystalline samples (15-35 mg) loaded into precalibrated containers and 
sealed with epoxy resin under a dinitrogen-helium atmosphere. Diamagnetic susceptibility corrections ${ }^{17}$ were applied. Mössbauer spectra were determined with a constant-acceleration spectrometer equipped with a ${ }^{57} \mathrm{Co}$ source in a Rh matrix. Zero-field measurements were made between 4.2 and $300 \mathrm{~K}$, with the spectrometer operating in the time mode and the source maintained at room temperature. Magnetically perturbed spectra were obtained in longitudinally applied fields up to $80 \mathrm{kOe}$, with the source and absorber at $4.2 \mathrm{~K}$. Polycrystalline samples were dispersed in boron nitride powder and sealed with epoxy resin in plastic sample holders. Isomer shifts are reported relative to $\mathrm{Fe}$ metal at $4.2 \mathrm{~K}$. EPR spectra were recorded at X-band frequencies at $c a$ $19 \mathrm{~K}$ on a Varian E-109 spectrometer. Solution susceptibilities were determined by a NMR method. ${ }^{18}$ Solvent susceptibilities were taken from the literature ${ }^{19}$ and corrections for solution density changes with temperature were applied.

\section{RESULTS AND DISCUSSION}

The following clusters, 1-9, are of primary interest in this investigation. The monocapped prismane structure of 1 has been crystallographically established. ${ }^{9}$ The basket configurations are assigned to 2-6 on the basis of the crystal structures of 7 and 8 , and the correspondence of spectroscopic properties to those of the structurally defined clusters. All clusters are mixed-valence but individual $\mathrm{Fe}^{\mathrm{Il}}$ or
$\mathrm{Fe}^{\mathrm{II}}$ sites, if present, cannot be recognized unambiguously from crystallographic data. As will be seen, 'H NMR spectra are consistent with retention of the basket structure of halide clusters in solution. $\mathrm{Fe}_{7} \mathrm{~S}_{6}\left(\mathrm{PEt}_{3}\right)_{4} \mathrm{Cl}_{3}(1) ; \mathrm{Fe}_{6} \mathrm{~S}_{6}\left(\mathrm{PEt}_{3}\right)_{4} \mathrm{Cl}_{2}(2) ; \mathrm{Fe}_{6} \mathrm{Se}_{6}$ $\left(\mathrm{PEt}_{3}\right)_{4} \mathrm{Cl}_{2}(3) ; \mathrm{Fe}_{6} \mathrm{~S}_{6}\left(\mathrm{PEt}_{3}\right)_{4} \mathrm{Br}_{2}(4) ; \mathrm{Fe}_{6} \mathrm{~S}_{6}\left(\mathrm{PEt}_{3}\right)_{4} \mathrm{I}_{2}$ (5); $\mathrm{Fe}_{6} \mathrm{~S}_{6}\left(\mathrm{PEt}_{3}\right)_{4}(\mathrm{SPh})_{2}(6) ; \mathrm{Fe}_{6} \mathrm{~S}_{6}\left(\mathrm{PBu}_{3}\right)_{4} \mathrm{Cl}_{2}(7)$; $\mathrm{Fe}_{6} \mathrm{~S}_{6}\left(\mathrm{PEt}_{3}\right)_{4}\left(\mathrm{~S}-p-\mathrm{C}_{6} \mathrm{H}_{4} \mathrm{Br}\right)_{2}(\mathbf{8}) ;\left[\mathrm{Fe}_{6} \mathrm{~S}_{6}\left(\mathrm{PEt}_{3}\right)_{6}\right]^{1+}$ (9).

\section{Electronic properties}

Ground spin states, other magnetic aspects and electronic distributions in clusters 1-7 have been examined using the methods of magnetic susceptibility, magnetization and ${ }^{57} \mathrm{Fe}$ Mössbauer spectroscopy. Related results for cluster 9 have been reported ${ }^{12}$ and certain data are included here for comparison purposes. Before each measurement, the purity of a given compound was established from its distinctive, isotropically shifted ${ }^{1} \mathrm{H}$ NMR spectrum (vide infra) previously recorded on an analytical sample. ${ }^{3,11,12}$ Magnetic and Mössbauer results are contained in Tables 1 and 2 respectively, and selected data are displayed in Figs 2-7. The numerical designation of $\mathrm{Fe}$ sites in Table 2 and Fig. 1 correspond. The Curie constant in the CurieWeiss law, $\chi^{\mathrm{M}}=C /(T-\theta)$, has the values $C=0.375,1.000$ and $1.875 \mathrm{emu} \mathrm{K} \mathrm{mol}{ }^{-1}$ for pure $S=1 / 2, S=1$ and $S=3 / 2$ states, respectively, when $g_{\mathrm{e}}=2$.

Table 1. Magnetic properties of clusters $1-7^{a}$

\begin{tabular}{lcccccccc}
\hline \multicolumn{1}{c}{ Cluster } & $T(\mathrm{~K})^{b}$ & $\begin{array}{c}C \\
\left.(\mathrm{emu} \mathrm{K} \mathrm{mol})^{-1}\right)\end{array}$ & $\mathrm{S}$ & $\begin{array}{c}\mu_{\mathrm{eff}} \\
\left(\mu_{\mathrm{B}}\right)\end{array}$ & $\theta(\mathrm{K})$ & $g_{\mathrm{e}}$ & $\begin{array}{c}D \\
\left(\mathrm{~cm}^{-1}\right)\end{array}$ & $|E / D|$ \\
\hline $\mathrm{Fe}_{7} \mathrm{~S}_{6}\left(\mathrm{PEt}_{3}\right)_{4} \mathrm{Cl}_{3}$ & $6-45$ & 0.581 & $1 / 2$ & 2.16 & -1.88 & - & - & - \\
$\mathrm{CDCl}_{3}$ soln & 298 & - & & $3.95^{c, d}$ & - & - & - & - \\
$\mathrm{Fe}_{6} \mathrm{~S}_{6}\left(\mathrm{PEt}_{3}\right)_{4} \mathrm{Cl}_{2}$ & $6-150$ & 0.993 & 1 & 2.82 & -4.49 & 1.89 & -17.3 & 0.18 \\
$\mathrm{CD}_{2} \mathrm{Cl}_{2}$ soln & $190-302$ & - & & $2.74-2.81^{c, s}$ & - & - & - & - \\
$\mathrm{Fe}_{6} \mathrm{Se}_{6}\left(\mathrm{PEt}_{3}\right)_{4} \mathrm{Cl}_{2}$ & $6-75$ & 1.211 & 1 & 3.11 & -1.28 & 2.06 & -2.27 & 0.23 \\
$\mathrm{CD}_{2} \mathrm{Cl}_{2}$ soln & $190-302$ & - & & $3.30-3.44^{c, f}$ & - & - & - & - \\
$\mathrm{Fe}_{6} \mathrm{~S}_{6}\left(\mathrm{PEt}_{3}\right)_{4} \mathrm{Br}_{2}$ & $6-100$ & 0.962 & 1 & 2.76 & -8.80 & 1.80 & -40.5 & 0.11 \\
$\mathrm{Fe}_{6} \mathrm{~S}_{6}\left(\mathrm{PEt}_{3}\right)_{4} \mathrm{I}_{2}$ & $6-75$ & 1.174 & 1 & 3.07 & -24.2 & 1.79 & - & - \\
$\mathrm{Fe}_{6} \mathrm{~S}_{6}\left(\mathrm{PEt}_{3}\right)_{4}\left(\mathrm{SPh}_{2}{ }^{g}\right.$ & 296 & - & 1 & 2.72 & - & - & - & - \\
{$\left[\mathrm{Fe}_{6} \mathrm{~S}_{6}\left(\mathrm{PEt}_{3}\right)_{6}\right]^{1+h}$} & $6-30$ & 0.485 & $1 / 2$ & 1.98 & -0.85 & - & - & - \\
\hline
\end{tabular}

${ }^{a}$ All data refer to the solid state unless otherwise indicated.

${ }^{b}$ Curie region.

${ }^{c}$ Calculated from the Curie law, $\mu_{\mathrm{eff}}=2.83\left(\chi^{\mathrm{M}} T\right)^{1 / 2}$; moments increase monotonically with increasing temperature,

${ }^{d, e}$ Comparison solution/solid state moments at $300-302 \mathrm{~K}:{ }^{d} 3.95 / 4.09 ;{ }^{e} 2.81 / 3.04$.

${ }^{f} \mu_{\mathrm{eff}}=3.40 \mu_{\mathrm{B}}$ in solid state, $200 \mathrm{~K}$.

${ }^{s}$ Toluene solution.

${ }^{h}$ Reference 12. 
Table 2. Mössbauer spectroscopic results at $4.2 \mathrm{~K}$

\begin{tabular}{|c|c|c|c|c|c|c|c|}
\hline Cluster & Site & $\begin{array}{l}\delta^{a, b} \\
(\mathrm{~mm} \mathrm{~s}\end{array}$ & $\begin{array}{l}\Delta E_{\mathrm{Q}}^{b} \\
\left.-{ }^{b}\right)\end{array}$ & $\begin{array}{c}A_{\mathrm{x}}{ }^{c} \\
\left(H_{\mathrm{x}}\right)^{d}\end{array}$ & $\begin{array}{c}A_{\mathrm{y}} \\
\left(H_{\mathrm{y}}\right) \\
\left(\mathrm{mm} \mathrm{s}^{-1}\right)\end{array}$ & $\begin{array}{c}A_{\mathbf{z}} \\
\left(H_{z}\right)\end{array}$ & $\eta^{e}$ \\
\hline \multirow[t]{3}{*}{$\mathrm{Fe}_{7} \mathrm{~S}_{6}\left(\mathrm{PEt}_{3}\right)_{4} \mathrm{Cl}_{3}$} & 1 & 0.67 & 0.51 & $\begin{array}{r}0.005 \\
(-0.37)\end{array}$ & $\begin{array}{r}0.748 \\
(-55.0)\end{array}$ & $\begin{array}{r}0.649 \\
(-47.7)\end{array}$ & 0.79 \\
\hline & 2 & 0.36 & 0.87 & $\begin{array}{c}-0.008 \\
(0.59)\end{array}$ & $\begin{array}{c}-0.161 \\
(11.8)\end{array}$ & $\begin{array}{c}-0.231 \\
(17.0)\end{array}$ & 1.00 \\
\hline & 3 & 0.36 & 0.28 & $\begin{array}{c}-0.007 \\
(0.52)\end{array}$ & $\begin{array}{c}-0.001 \\
(0.07)\end{array}$ & $\begin{array}{c}-0.966 \\
(73.2)\end{array}$ & 0.24 \\
\hline \multirow[t]{3}{*}{$\mathrm{Fe}_{6} \mathrm{~S}_{6}\left(\mathrm{PEt}_{3}\right)_{4} \mathrm{Cl}_{2}$} & 1 & 0.63 & 0.60 & $\begin{array}{c}-1.120 \\
(88.7)\end{array}$ & $\begin{array}{c}-0.397 \\
(10.0)\end{array}$ & $\begin{array}{c}-0.058 \\
(7.7)\end{array}$ & 1.00 \\
\hline & 2 & 0.34 & 0.87 & $\begin{array}{r}0.440 \\
(-34.9)\end{array}$ & $\begin{array}{r}0.694 \\
(-17.4)\end{array}$ & $\begin{array}{r}0.939 \\
(-125)\end{array}$ & 0.22 \\
\hline & 3 & 0.32 & 1.10 & $\begin{array}{r}0.448 \\
(-35.5)\end{array}$ & $\begin{array}{r}0.090 \\
(-2.3)\end{array}$ & $\begin{array}{c}0.023 \\
(-3.1)\end{array}$ & 0.81 \\
\hline \multirow[t]{3}{*}{$\mathrm{Fe}_{6} \mathrm{Se}_{6}\left(\mathrm{PEt}_{3}\right)_{4} \mathrm{Cl}_{2}$} & 1 & 0.64 & 0.65 & $\begin{array}{c}-1.013 \\
(135)\end{array}$ & $\begin{array}{c}-0.614 \\
(78.3)\end{array}$ & $\begin{array}{c}-0.318 \\
(44.7)\end{array}$ & 0.00 \\
\hline & 2 & 0.35 & 1.08 & $\begin{array}{r}0.882 \\
(-117)\end{array}$ & $\begin{array}{r}0.567 \\
(-72.3)\end{array}$ & $\begin{array}{r}0.616 \\
(-86.7)\end{array}$ & 0.40 \\
\hline & 3 & 0.40 & 1.29 & $\begin{array}{r}1.293 \\
(-172)\end{array}$ & $\begin{array}{r}0.843 \\
(-107)\end{array}$ & $\begin{array}{r}0.578 \\
(-81.3)\end{array}$ & 1.00 \\
\hline \multirow[t]{3}{*}{$\mathrm{Fe}_{6} \mathrm{~S}_{6}\left(\mathrm{PEt}_{3}\right)_{4} \mathrm{Br}_{2}$} & 1 & 0.61 & 0.56 & $\begin{array}{c}-0.019 \\
(0.77)\end{array}$ & $\begin{array}{c}-0.017 \\
(0.06)\end{array}$ & $\begin{array}{c}-0.364 \\
(44.3)\end{array}$ & 0.00 \\
\hline & 2 & 0.33 & 0.79 & $\begin{array}{r}0.426 \\
(-17.4)\end{array}$ & $\begin{array}{r}0.269 \\
(-0.91)\end{array}$ & $\begin{array}{r}0.121 \\
(-14.7)\end{array}$ & 1.00 \\
\hline & 3 & 0.29 & 1.04 & $\begin{array}{r}0.450 \\
(-18.3)\end{array}$ & $\begin{array}{r}0.013 \\
(-0.04)\end{array}$ & $\begin{array}{r}0.096 \\
(-11.7)\end{array}$ & 0.00 \\
\hline \multirow[t]{3}{*}{$\mathrm{Fe}_{6} \mathrm{~S}_{6}\left(\mathrm{PEt}_{3}\right)_{4} \mathrm{I}_{2}$} & 1 & 0.60 & 0.53 & $\begin{array}{c}-0.009 \\
(0.21)\end{array}$ & $\begin{array}{c}-0.007 \\
(0.00)\end{array}$ & $\begin{array}{c}-0.037 \\
(3.05)\end{array}$ & 0.03 \\
\hline & 2 & 0.38 & 0.84 & $\begin{array}{r}0.665 \\
(-15.4)\end{array}$ & $\begin{array}{l}0.015 \\
(0.00)\end{array}$ & $\begin{array}{r}0.258 \\
(-21.3)\end{array}$ & 0.47 \\
\hline & 3 & 0.23 & 0.95 & $\begin{array}{r}0.175 \\
(-4.06)\end{array}$ & $\begin{array}{c}0.008 \\
(0.00)\end{array}$ & $\begin{array}{r}0.120 \\
(-9.90)\end{array}$ & 0.47 \\
\hline \multirow[t]{3}{*}{$\mathrm{Fe}_{6} \mathrm{~S}_{6}\left(\mathrm{PEt}_{3}\right)_{4}(\mathrm{SPh})_{2}$} & 1 & 0.43 & 0.61 & - & - & - & \\
\hline & 2 & 0.39 & 0.86 & - & - & - & \\
\hline & 3 & 0.37 & 1.15 & - & - & - & \\
\hline \multirow[t]{3}{*}[\mathrm{Fe}_{6}\mathrm{S}_{6}(\mathrm{PEt}_{3})_{6}]{$\left(\mathrm{BF}_{4}\right)$} & 1 & 0.41 & 0.53 & $\begin{array}{r}0.564 \\
(-41.5)\end{array}$ & $\begin{array}{r}0.588 \\
(-43.2)\end{array}$ & $\begin{array}{r}0.459 \\
(-33.7)\end{array}$ & 0.00 \\
\hline & 2 & 0.41 & 0.88 & $\begin{array}{r}0.440 \\
(-32.3)\end{array}$ & $\begin{array}{r}0.359 \\
(-26.4)\end{array}$ & $\begin{array}{r}0.418 \\
(-30.7)\end{array}$ & 0.00 \\
\hline & 3 & 0.38 & 1.25 & $\begin{array}{r}0.027 \\
(-1.98)\end{array}$ & $\begin{array}{r}0.023 \\
(-1.69)\end{array}$ & $\begin{array}{r}0.018 \\
(-1.32)\end{array}$ & 1.00 \\
\hline $\mathrm{FeCl}_{2}\left(\mathrm{PEt}_{3}\right)_{2}^{f}$ & - & 0.65 & 2.90 & - & - & - & \\
\hline
\end{tabular}

${ }^{a}$ Relative to Fe metal at $4.2 \mathrm{~K}$.

${ }^{b}$ Spectral fits made with line widths in the range $0.25-0.34 \mathrm{~mm} \mathrm{~s}^{-1}$ and $\eta=0$.

${ }^{c}$ Magnetic hyperfine parameters for the $14.4 \mathrm{keV}$ excited state of ${ }^{57} \mathrm{Fe}$.

${ }^{d}$ Magnetic hyperfine field, $\mathrm{kOe}$; negative hyperfine fields oppose applied field.

c Asymmetry parameters, $\left(V_{\mathrm{xx}}-V_{\mathrm{yy}}\right) / V_{\mathrm{zz}}$.

${ }^{f} 200 \mathrm{~K}$. 

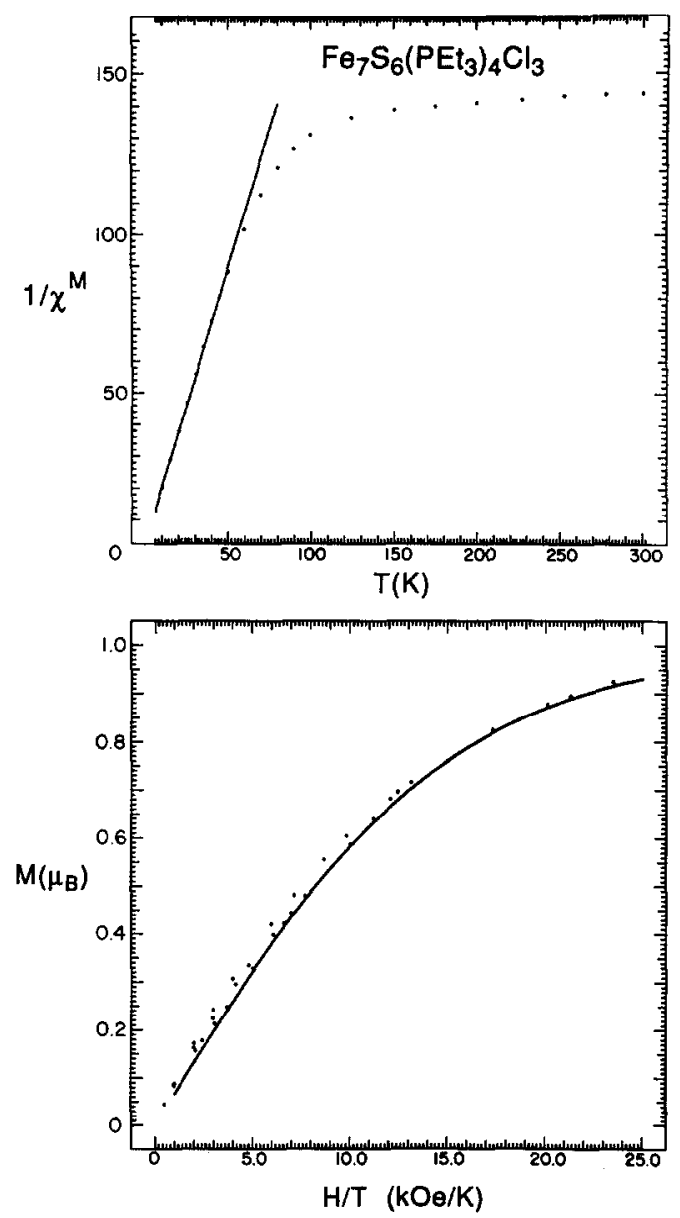

Fig. 2. Magnetic properties of cluster 1. Upper: temperature dependence of the reciprocal molar magnetic susceptibility. Lower : magnetization at applied fields of $12.5,25$ and $50 \mathrm{kOe}$ at $T=1.8-25 \mathrm{~K}$. Solid lines are calculated Curie behaviour for $S=1 / 2$ and theoretical fits to the magnetization data using the parameters in Table 1.

\section{(1) $\mathrm{Fe}_{7} \mathrm{~S}_{6}\left(\mathrm{PEt}_{3}\right)_{4} \mathrm{Cl}_{3}$}

(a) Magnetism. This odd-electron cluster formally contains $6 \mathrm{Fe}^{\mathrm{II}}+\mathrm{Fe}^{\mathrm{III}}$. As shown in Fig. 2, cluster 1 obeys the Curie-Weiss law at $6-45 \mathrm{~K}$, with $C=0.581 \mathrm{emu} \mathrm{K} \mathrm{mol}{ }^{-1}$. The magnetization was found to be field-independent and to follow a $S=1 / 2$ Brillouin function with saturation asymptotically approaching $g_{\mathrm{e}} S \mu_{\mathrm{B}}=1 \mu_{\mathrm{B}}$. The EPR spectrum in frozen THF solution at $20 \mathrm{~K}$ (not shown) reveals a nearly isotropic signal at $g_{\mathrm{e}}=2.02$, consistent with a doublet state. Also present are weaker resonances at $g_{\mathrm{e}}=5.2$ and 5.5 , which may be indicative of a small amount of the $S=3 / 2$ state. ${ }^{8}$ Physical mixtures of these spin states have been observed with $\mathrm{Fe}_{4} \mathrm{~S}_{4}$ cubane-type clusters. ${ }^{8}$ This situation could account (in part) for the posi-

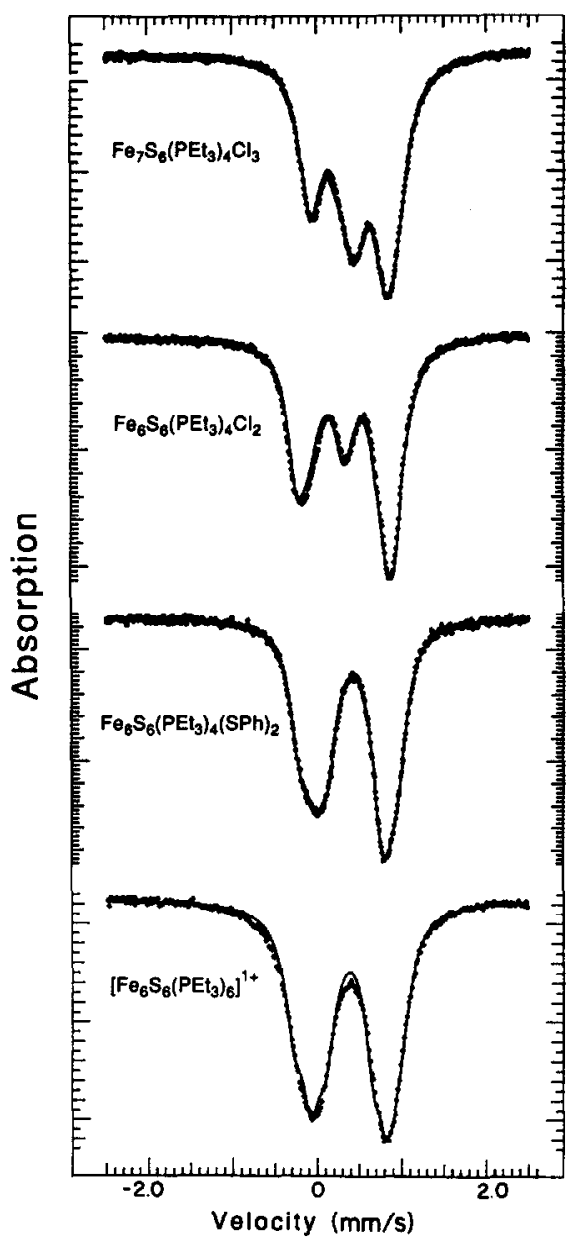

Fig. 3. Mössbauer spectra in zero applied magnetic field of clusters 1, 2, 6 and 9 (top to bottom). Solid lines are

fits to the data using the parameters in Table 2 .

tive deviation of the Curie constant from the $S=1 / 2$ value and the small shift of magnetization data in the lower $\mathrm{H} / \mathrm{T}$ region from the best fit for that state. The collective results support an $S=1 / 2$ ground state. The negative deviation of the susceptibility from the Curie-Weiss law above $45 \mathrm{~K}$ indicates the population of excited levels with $S>1 / 2$. At $298 \mathrm{~K}$, the essentially equal solution and solid state magnetic moments of $c a 4 \mu_{\mathrm{B}}$ show that the antiferromagnetic coupling (vide infra) is a molecular property.

(b) Mössbauer spectra. The monocapped prismane structure of 1 under idealized $C_{3 v}$ symmetry contains three $\mathrm{Fe}$ sites: $\mathrm{Fe}(1)\left(\mu_{3}-\mathrm{S}\right)\left(\mu_{4}-\mathrm{S}_{2}\right)_{2} \mathrm{Cl}$, $\mathrm{Fe}(2)\left(\mu_{3}-\mathrm{S}\right)_{2}\left(\mu_{4}-\mathrm{S}\right) \mathrm{P}$ and $\mathrm{Fe}(3)\left(\mu_{4}-\mathrm{S}\right)_{3} \mathrm{P}$. The $\mathrm{Fe}(2,3)$ sites have approximate trigonal pyramidal geometry while the $\mathrm{Fe}(1)$ site is more nearly tetrahedral. The Mössbauer spectrum in zero field, shown in Fig. 3, was fit with a constrained site 


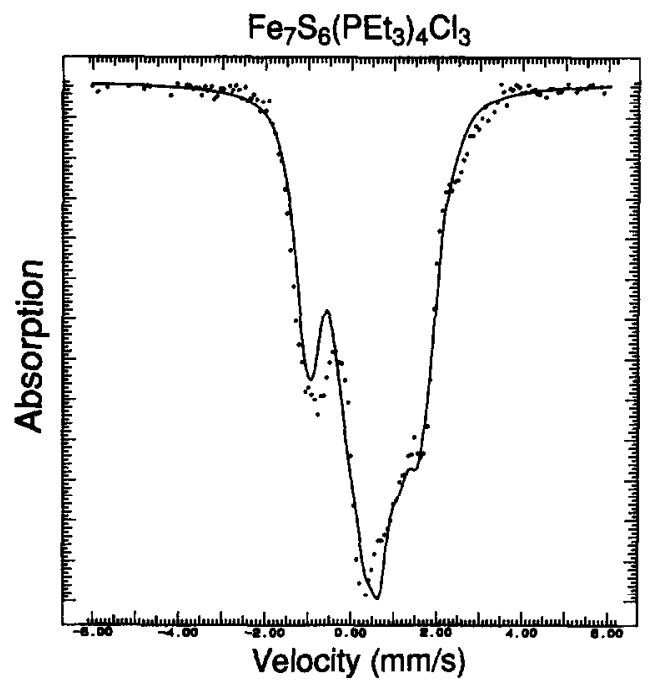

Fig. 4. Mössbauer spectrum of cluster 1 in an applied field of $60 \mathrm{kOe}$. The solid line is a theoretical fit to the data using the parameters in Table 2 with $S=1 / 2$.

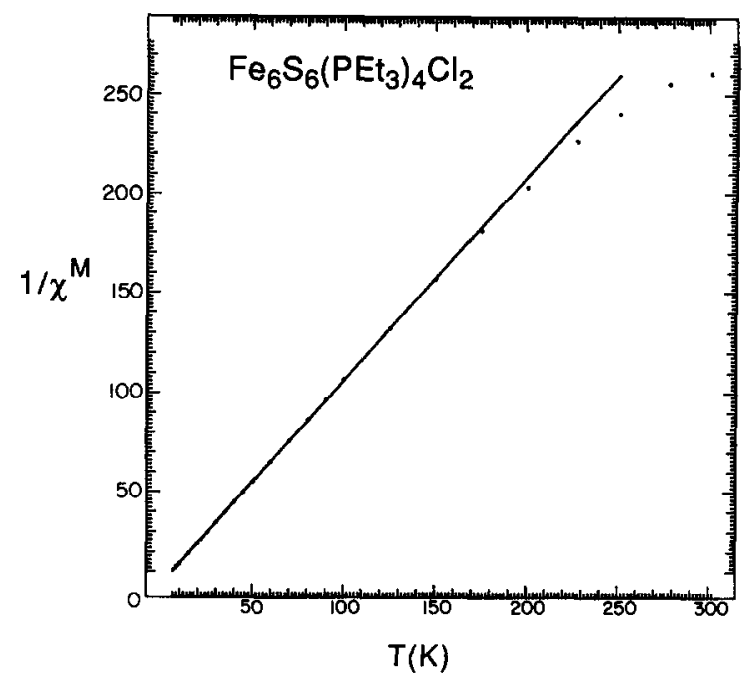

Fig. 5. Temperature dependence of the reciprocal molar susceptibility of cluster 2 . The solid line is a Curie-Weiss fit to the data using the parameters in Table 1. population of $3: 3: 1$. This allowed immediate identification of the $\mathrm{Fe}(3)$ site as that with isomer shift $\delta=0.36 \mathrm{~mm} \mathrm{~s}{ }^{1}$ and the (unusually) small quadrupole splitting $\Delta E_{\mathrm{Q}}=0.28 \mathrm{~mm} \mathrm{~s}^{-1}$. The $\mathrm{Fe}(2)$ site is common to 1 and to basket clusters 2-8, where it also approaches trigonal pyramidal stereochemistry. On the basis of this commonality, the $\mathrm{Fe}(2)$ site is assigned the doublet with the same isomer shift as $\mathrm{Fe}(3)$, but a larger quadrupole splitting. This leaves the $\mathrm{Fe}(1)$ site, at which chloride is bound, as that with the largest isomer shift $(0.67$ $\left.\mathrm{mm} \mathrm{s}^{-1}\right)$. This assignment is consistent with data for the pairs $\left(\mathrm{Me}_{4} \mathrm{~N}\right)_{2}\left[\mathrm{FeCl}_{4}\right]^{20} / \mathrm{Fe}\left(\mathrm{PEt}_{3}\right)_{2} \mathrm{Cl}_{2}(\approx 0.1$ $\left.\mathrm{mm} \mathrm{s} \mathrm{s}^{-1}\right)$ and $\left(\mathrm{Me}_{4} \mathrm{~N}\right)\left[\mathrm{FeCl}_{4}\right]^{20} / \mathrm{Fe}\left(\mathrm{PPh}_{3}\right) \mathrm{Cl}_{3}{ }^{21}$ $\left(\approx 0.05 \mathrm{~mm} \mathrm{~s}^{-1}\right)$, for which the indicated isomer shift differences correspond to a decrease in $\delta$ upon replacing chloride with phosphine.*

Magnetic Mössbauer spectra (not shown) exhibited movement of inner and outer features in opposite directions as the applied field was increased from 60 to $80 \mathrm{kOe}$, consistent with antiparallel spin coupling. The spectrum at $60 \mathrm{kOe}$ is shown in Fig. 4, together with a theoretical fit obtained using the method described below for the basket clusters and the parameters in Table 2. In this way, the $S=1 / 2$ ground state assignment was corroborated.

* Note, however, that the structure of $\mathrm{Fe}\left(\mathrm{PPh}_{3}\right) \mathrm{Cl}_{3}$ has not been established.
(2) $\mathrm{Fe}_{6} \mathrm{~S}_{6}\left(\mathrm{PEt}_{3}\right)_{4} \mathrm{X}_{2}\left(\mathrm{X}=\mathrm{Cl}^{-}, \mathrm{Br}^{-}, \mathrm{I}^{-}, \mathrm{PhS}^{-}\right)$and $\mathrm{Fe}_{6} \mathrm{Se}_{6}\left(\mathrm{PEt}_{3}\right)_{4} \mathrm{Cl}_{2}$

(a) Magnetism. This set consists of the even-electron basket clusters 2-6 which formally contain $4 \mathrm{Fe}^{\mathrm{II}}+2 \mathrm{Fe}^{\mathrm{III}}$. As will be evident, certain electronic aspects of these clusters are unusual and cannot be satisfactorily interpreted. Clusters 2-5 display Curie behaviour of magnetic susceptibilities over appreciable temperature intervals but in several cases with large Weiss constants (Table 1). Curie constants are fairly close to the value for a $S=1$ state. The results for cluster $\mathbf{2}$, which are fairly typical for compounds in this set, are shown in Fig. 5. Deviations from Curie behaviour are such as to indicate the population of higher spin states or a small TIP contribution.

Magnetization data for clusters 2-5 obtained at $1.8-100 \mathrm{~K}$ and at three applied fields are presented in Fig. 6. All show nested curves corresponding to different values of the applied field and indicating that the zero-field splitting parameter $D \neq 0$. The data were analysed under the simple spin Hamiltonian (1)

$$
H=D\left[S_{\mathrm{z}}{ }^{2}-S(S+1) / 3\right]+E\left(S_{\mathrm{x}}{ }^{2}-S_{\mathrm{y}}{ }^{2}\right)+g_{\mathrm{e}} \mu_{\mathrm{B}} \mathbf{H} \cdot \mathbf{S},
$$

with $S=1$ by calculating the spin projection along the magnetic field direction; $E$ is the rhombic splitting parameter and the other symbols have their usual meanings. The experimental data were simulated from the Curie to the saturation region by 


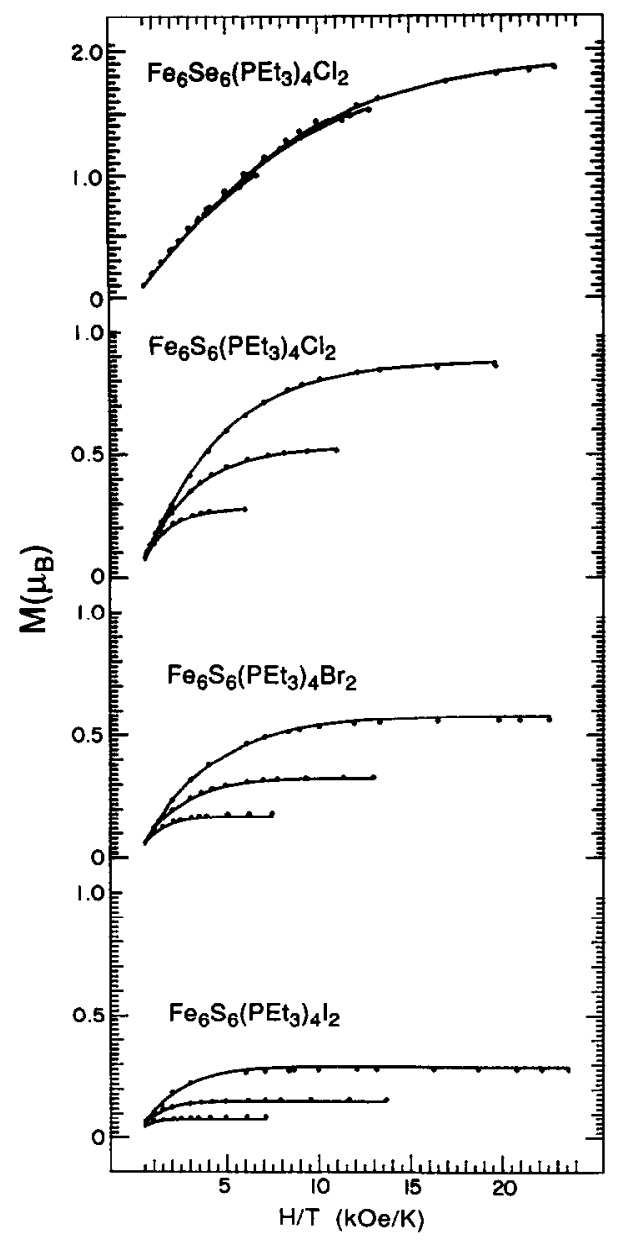

Fig. 6. Magnetization behaviour of clusters 3, 2, 4 and 5 (top to bottom). For each cluster, curves in ascending order refer to applied fields of $12.5,25$ and $50 \mathrm{kOe}$. The solid lines are theoretical fits to the data using the parameters in Table 1.

least-squares fits, using a simplex algorithm and the parameters in Table 1. In order to obtain satisfactory fits, it was necessary to use $D<0$ and $E / D>0$ with inclusion of $g_{\mathrm{e}} \neq 2$. The algorithm allowed for simultaneous fits of the data at the three applied fields.

The behaviour of cluster 3 is the simplest, in that the saturation magnetization of $2 \mu_{\mathrm{B}}$ is nearly reached and the data are well fit with unexceptional parameters for a spin-triplet, including a zero-field splitting (ZFS) of $-2.27 \mathrm{~cm}^{-1}$. However, the saturation magnetization of the remaining clusters $(2$, $4,5)$ becomes increasingly and markedly suppressed in the order $\mathrm{X}=\mathrm{Cl}^{-}>\mathrm{Br}^{-}>\mathrm{I}$, reaching a minimum with cluster $5\left(0.29 \mu_{\mathrm{B}}\right.$ at $\left.50 \mathrm{kOe}\right)$. Fits required increasing large negative $D$ values, which are consistent with the respective Weiss constants. The suppression effect is intramolecular in origin because a

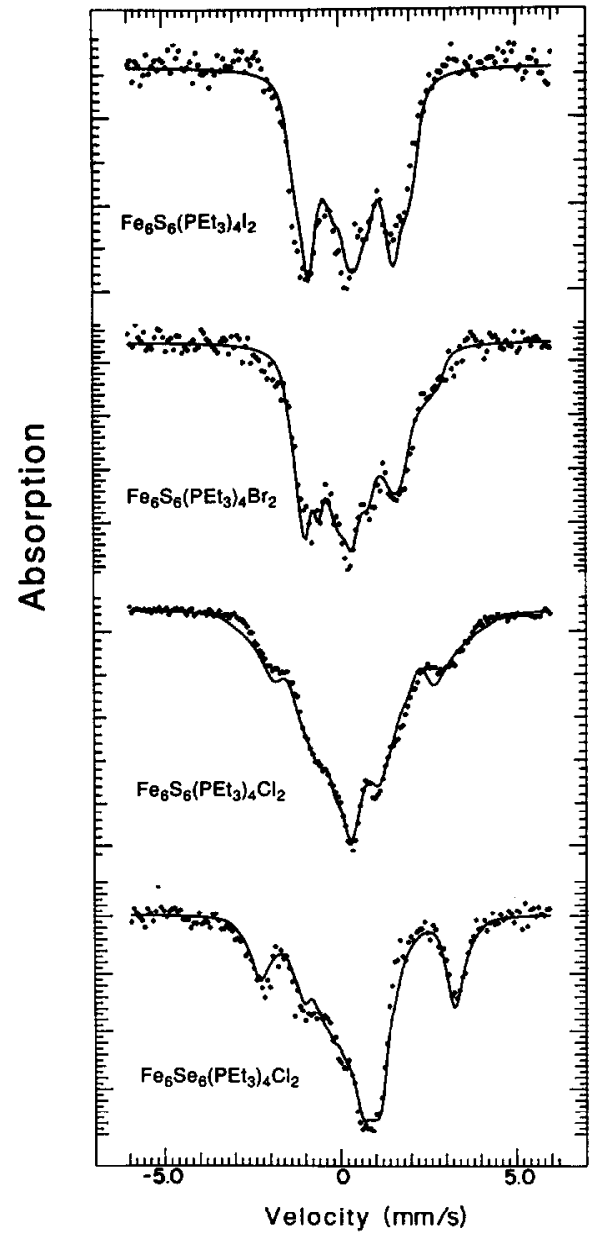

Fig. 7. Mössbauer spectra of clusters 5, 4, 2 and 3 (top to bottom) at $4.2 \mathrm{~K}$ in an applied field of $80 \mathrm{kOe}$. The solid lines are fits to the data using the parameters in Table 2 with $S=1$.

magnetization measurement of a $41 \mathrm{mM}$ solution of $\mathbf{4}$ in dichloromethane yielded essentially the same result as the polycrystalline sample.

While the foregoing treatment of magnetization is obviously phenomenological, it is presented as a means of comparing and contrasting the behaviours of clusters 2-5. The large ZFS are not without precedent and are seemingly within physical reason for 2-4. While no meaningful comparison can be made with other systems, owing to the uniqueness of the basket cluster topology, we note that apparent ZFS values of up to $c a 20 \mathrm{~cm}^{-1}$ have been observed for certain $S=5 / 2 \mathrm{Fe}^{\mathrm{III}}$ porphyrins, ${ }^{22,23}$ and that for two $S=1$ planar $\mathrm{Fe}^{\mathrm{II}}$ complexes values near 70 $\mathrm{cm}^{-1}$ have been obtained. ${ }^{24,25}$ All of these are obviously apparent values, dependent on the theoretical formalism. (For a discussion of this point, cf. ref. 22.) In the present case, we are applying a spin 
Hamiltonian formalism to a general case where it has not been otherwise tested; viz. to polynuclear spin-coupled systems with incompletely quenched orbital angular momentum and probable spin-orbit interactions at local metal sites.

Thiolate cluster 6 is the most anomalous member of the set. In the solid state it does not exhibit a Curic region (nor any indication of a Curie paramagnetic impurity), is very weakly paramagnetic at $6 \mathrm{~K}$ and shows nesting of magnetization curves with a nearly zero saturation magnetization $\left(0.1 \mu_{\mathrm{B}}\right.$ at 50 $\mathrm{kOe}$; data not shown). It is conceivable that this species represents an extension of the behaviour of 2-5, but from the information available we are unable to demonstrate the ground state spin. Moreover, in toluene solution, $\mu_{\mathrm{eff}}=2.72 \mu_{\mathrm{B}}$, essentially the same as the solution moment for 2 , for which a triplet ground state has been established. On this limited evidence, the $S=1$ ground state designation has been entered in Table 1 . In the solid state the core structures of $\mathbf{8}$, the magnetic properties of which are quite similar to those of 6 , and also of 7 , which bears a similar relationship to 2 , are virtually congruent. ${ }^{3,11}$ It is unlikely, in either the solid or solution states, that the magnetic differences between $\mathbf{6}$ and other basket clusters arise from large core structural differences.

(b) Solution properties. In dichloromethane solutions at 190-302 K, magnetic moments of clusters
2 and 3 show a near-Curie dependence of magnetic susceptibilities with values consistent with an $S=1$ ground state. Ranges in magnetic moments over the temperature range are given in Table 1 . The larger magnetic moments of selenide cluster 3 vs sulphide cluster 2 in solution and in the solid state (Table 1) are consistent with an earlier observation of smaller antiferromagnetic coupling in $\mathrm{Fe}_{4} \mathrm{Se}_{4}$ than in $\mathrm{Fe}_{4} \mathrm{~S}_{4}$ clusters. ${ }^{26}$ The variable-temperature ${ }^{1} \mathrm{H}$ NMR spectra of clusters 2 and 3 are presented in Figs 8 and 9 , respectively. The occurrence of two equally intense methylene and methyl resonances for 2 , from the inequivalent sites $\mathrm{Fe}(2,3)$, over the 190 $300 \mathrm{~K}$ range, demonstrates retention of the solid state structure in solution. The spectra of $\mathbf{3}$ are similar but the methyl resonances are not well resolved. Line broadening at the lower temperatures is ascribed to the effect of increasing cluster paramagnetism rather than any dynamic process. The isotropic shifts of 3 are considerably larger than those of 2 , the difference being $32 \%$ at $300 \mathrm{~K}$. The effect is qualitatively consistent with the magnetic susceptibilities and suggests that the isotropic shifts have a significant contact component. Other evidence for a contact contribution is the alternating phenyl proton shifts of cluster $6 .^{3}$ However, the shifts of 2 and 3 do not scale linearly with the susceptibilities, as would be the case for pure contact shifts. This indicates the presence of dipolar

\section{$\mathrm{Fe}_{6} \mathrm{~S}_{6}\left(\mathrm{PEt}_{3}\right)_{4} \mathrm{Cl}_{2}$}

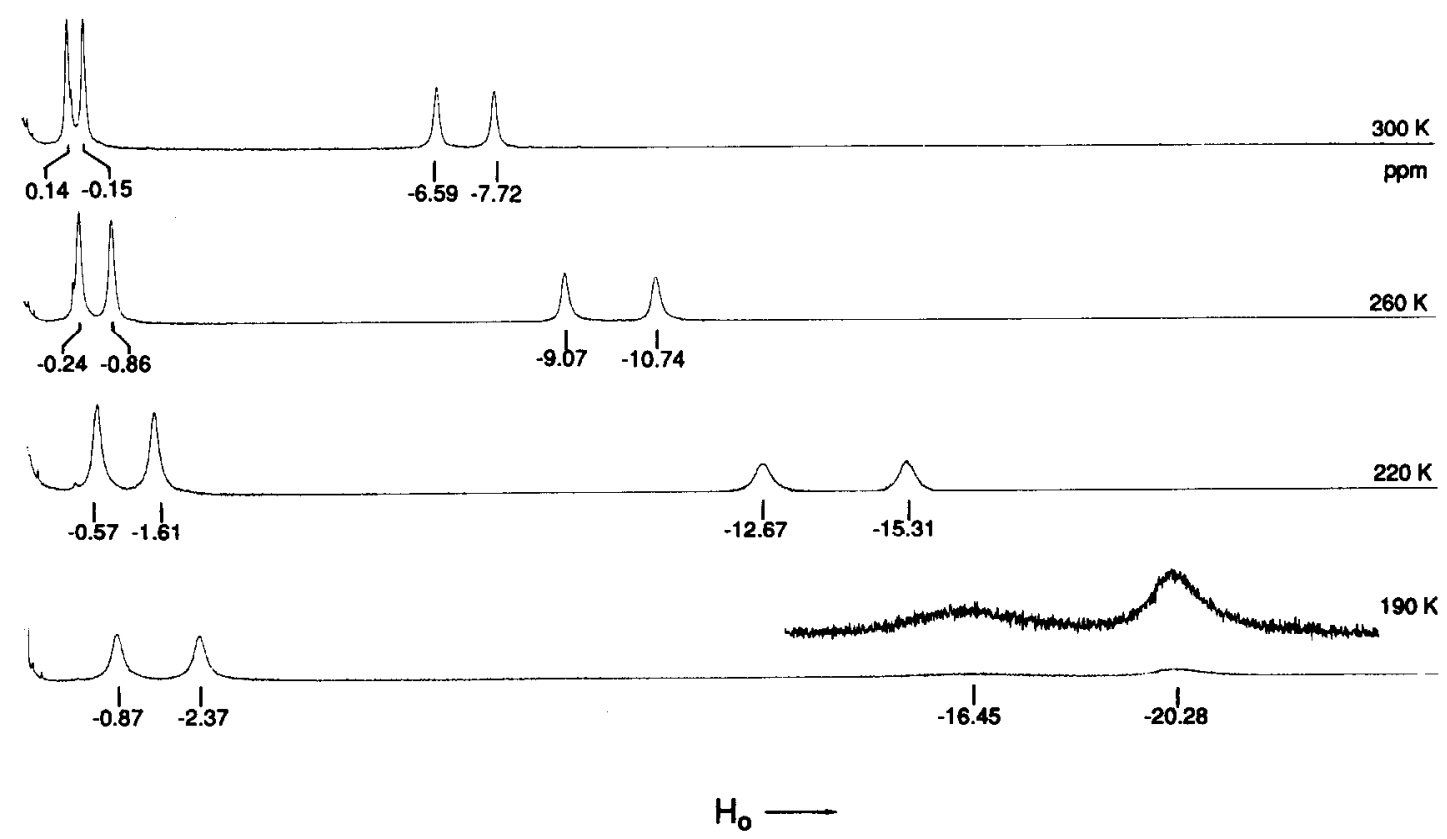

Fig. 8. Temperature dependence of the ${ }^{1} \mathrm{H}$ NMR spectra of cluster 2 in $\mathrm{CD}_{2} \mathrm{Cl}_{2}$ solution; chemical shifts are indicated. 

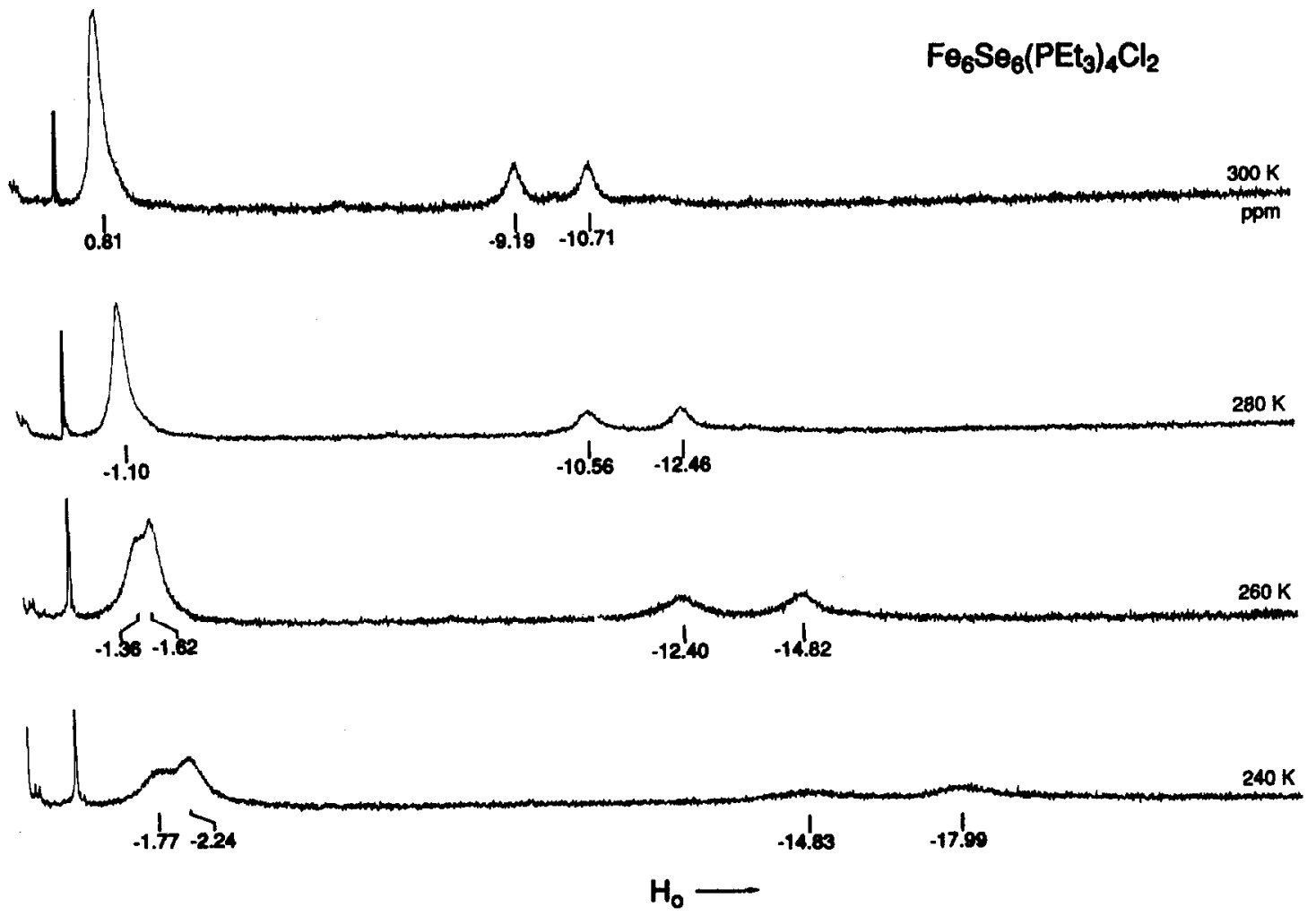

Fig. 9. Temperature dependence of the ${ }^{1} \mathrm{H}$ NMR spectra of cluster 3 in $\mathrm{CD}_{2} \mathrm{Cl}_{2}$ solution; chemical shifts are indicated.

shifts, a feature not unexpected in molecules with significant ZFS and magnetic anisotropies.

(c) Mössbauer spectra. Basket clusters contain three types of Fe sites (Fig. 1): $\mathrm{Fe}(1)\left(\mu_{3}-\mathrm{S}\right)_{2}\left(\mu_{4}-\mathrm{S}\right) \mathrm{L}$, $\operatorname{Fe}(2)\left(\mu_{3}-\mathbf{S}\right)_{2}\left(\mu_{4}-\mathbf{S}\right) \mathbf{P}$ and $\mathrm{Fe}(3)\left(\mu_{2}-\mathbf{S}\right)\left(\mu_{3}-\mathbf{S}\right)_{2} \mathbf{P}$. The first of these is roughly tetrahedral, while the other two have distorted trigonal pyramidal geometry. The zero-field Mössbauer spectra of clusters 2 and 6 are displayed in Fig. 3; the spectrum of 2 closely resembles those of 3-5 (not shown), in containing three resolved features. All spectra were analysed with a $1: 1: 1 \mathrm{Fe}$ site population. The assignment of the $\mathrm{Fe}(2)$ site has been discussed; that of the $\mathrm{Fe}(3)$ site in 6 is based on correlation of the largest quadrupole splitting $\left(1.15 \mathrm{~mm} \mathrm{~s}^{-1}\right)$ with those in 2-5 $\left(0.95-1.29 \mathrm{~mm} \mathrm{~s}^{-1}\right)$. This leaves the $\mathrm{Fe}(1)$ sites in 2-5 and in 6 as those with $\delta=0.60-0.64$ and $0.43 \mathrm{~mm} \mathrm{~s}^{-1}$, respectively. The relatively large isomer shift change $\left(0.20 \mathrm{~mm} \mathrm{~s}^{-1}\right)$ upon replacing chloride (2) with thiolate (6), while the isomer shifts of the other sites change by no more than $0.05 \mathrm{~mm} \mathrm{~s}^{-1}$, is another indication that the $\mathrm{Fe}(1)$ sites contain halide. Also, the small variation in isomer shift with halide is consistent with previous behaviour of $\mathrm{FeS}_{3} \mathrm{X}$ sites in prismane clusters. ${ }^{13-16}$ While we cannot insist on these site assignments, they are internally consistent within the cluster set 1-6 and we proceed on that basis.

Substitution of thiolate for chloride in tetrahedral $\mathrm{FeS}_{3} \mathrm{X}$ units of prismane and cubane-type clusters has been found to cause a decrease of $c a 0.05-0.11$ $\mathrm{mm} \mathrm{s}^{-1}$ in isomer shift. ${ }^{13,27,28}$ In the basket clusters this results in the much larger change of $0.20 \mathrm{~mm}$ $\mathrm{s}^{-1}$, as just noted. The smaller change in isomer shift in the cubane-type clusters has been previously considered in terms of a decrease in covalency of the $\mathrm{Fe}-\mathrm{L}$ bond. In the case of the present clusters, however, the much larger change in $\delta$ values suggests that there is a detectable change in core charge delocalization upon ligand substitution. Earlier, it had been shown that in clusters containing welldefined $\mathrm{Fe}$ (mean) oxidation states, $s$, isomer shifts of tetrahedral $\mathrm{FeS}_{4}$ sites follow the empirical linear relationship of eq. (2) :29

$$
\delta=1.44-0.43 s \text {. }
$$

Its application to 6 yields an oxidation state of $2.35+$ at the $\mathrm{Fe}(1)$ sites, very close to the cluster mean oxidation state of $2.33+$ and, therefore, consistent with a highly delocalized cluster. Based on structural results for $\left[\mathrm{Fe}_{4} \mathrm{~S}_{4}(\mathrm{SR})_{4}\right]^{1-, 2-, 3-1,7,8,30}$ the mean $\mathrm{Fe}-\mathrm{S}$ terminal bond length of $2.255 \AA$ in 
$\mathbf{8}$ is somewhat more consistent with $2.50+$ than $2.33+$, but not with $2.67+$. No such $\delta / s$ relationship has been established for tetrahedral $\mathrm{FeS}_{3} \mathrm{Cl}$ sites. We surmise that the chloride-bound sites $\mathrm{Fe}(1)$, on charge neutralization grounds, are biased toward iron(III) character, in which case the large isomer shifts result from the removal of electron density from orbitals with $4 s$ character rather than an increase in the $3 d$-type orbitals. The isomer shift change of $0.05 \mathrm{~mm} \mathrm{~s}^{-1}$ at the $\mathrm{Fe}(2,3)$ sites is consistent with a marginal increase in iron(II) character, in apparent response to the effect of chloride at $\mathrm{Fe}(1)$. The mean $\mathrm{Fe}-\mathrm{Cl}$ distance in $7(2.193 \AA)$, when compared with the value in $\left[\mathrm{Fe}_{4} \mathrm{~S}_{4} \mathrm{Cl}_{4}\right]^{2-}$ $[2.216(2) \AA],{ }^{31}$ is compatible with a mean oxidation state $>2.50+$. In this argument, the site with the most ferric character has the largest, rather than the smallest, isomer shift. Whatever the merits of this interpretation it is certainly the case that, on the basis of structural ${ }^{2,8-10}$ and spectroscopic evidence, clusters 1-6, as all other mixed-valence synthetic and biological $\mathrm{Fe}-\mathrm{S}$ clusters with a nuclearity of 3 or larger, are, electronically, largely delocalized systems. Note that for cluster $\mathbf{9}$, which formally contains $5 \mathrm{Fe}^{\mathrm{II}}+\mathrm{Fe}^{\mathrm{II}}$ and has only phosphine terminal ligands, isomer shifts are essentially identical.

Magnetically perturbed Mössbauer spectra of clusters 2-5 are presented in Fig. 7. For 2 and 3, where the effect is the clearest, an increase in the applied field from 60 to $80 \mathrm{kOe}$ caused features in the wings and in the central portions of the spectra to move in opposite directions, signifying antiferromagnetic coupling, which produces a $S=1$ ground state. Solid lines are theoretical fits using the Hamiltonian (3) and a fitting program which is a modified version of the Lang-Dale minimizer. ${ }^{32}$

$$
H=G_{\mathrm{e}} \mu_{\mathrm{B}} \mathbf{H} \cdot \mathbf{S}+\Sigma\left[A(i) \cdot \mathbf{I}_{\mathrm{i}} \cdot \mathbf{S}-g_{\mathrm{n}} \mu_{\mathrm{n}} \mathbf{H} \cdot \mathbf{I}_{\mathrm{i}}+H_{\mathrm{Q}}(i)\right]
$$

$$
H_{\mathrm{Q}}=\left(e Q V_{\mathrm{zz}} / 12\right)\left[3 I_{\mathrm{z}}{ }^{2}-15 / 4+\eta\left(I_{\mathrm{x}}{ }^{2}+I_{\mathrm{y}}{ }^{2}\right)\right]
$$

Fits were performed in the fast relaxation regimc with an imposed $1: 1: 1$ site ratio, assumed random crystallite orientation, and otherwise as described for $\left[\mathrm{Fe}_{4} \mathrm{~S}_{4}(\mathrm{SR})_{4}\right]^{3-}$ clusters. ${ }^{7,8}$ The parameters for each site are the magnetic hyperfine coupling constants $A_{\mathrm{x}}, A_{\mathrm{y}}$ and $A_{\mathrm{z}}$, the EFG asymmetry parameter $\eta$, and the sign of the principal component of the EFG $\left(V_{z z}\right)$. Values used in the spectral fits are listed in Table 2. Deviations of the theoretical fits from experimental points may arise from intermediate relaxation phenomena, as observed in related clusters, ${ }^{6}$ and from the presence of crystallites. Theoretical fits of the magnetic spectra required progressively smaller values of hyperfine coupling constants along the halide series as the spectral width narrows, paralleling the monotonic decrease in the saturation magnetization for 2-5. Inasmuch as these clusters all appear to have $S=1$ ground states, they would be expected to have about the same $A_{\mathrm{i}}$ values at a given type of $\mathrm{Fe}$ site. That they do not, reflects differences in orbital states of the individual $\mathrm{Fe}$ sites. The spectrum of 6 (not shown) evidenced a small perturbation in an $80 \mathrm{kOe}$ applied field ( $c a 2.8 \mathrm{~mm} \mathrm{~s}^{-1}$ spectral width) and resembled somewhat that of 5 . Owing to the uncertainty in the ground state, the spectrum was not analysed.

In the basket clusters 2-5, phosphine-ligated sites $\mathrm{Fe}(2,3)$ show positive hyperfine coupling constants and correspondingly negative hyperfine fields. Site $\mathrm{Fe}(1)$, thought to be more ferric-like, has oppositely signed parameters while the sites $\mathrm{Fe}(1-3)$, in the allphosphine basket cluster 9 have positive $A_{\mathrm{i}}$ and negative $H_{\mathrm{i}}$ parameters. These results are consistent with the same sign of the isotropic shifts of 2-5 and $9,1^{12}$ so long as these are mainly contact in origin, as appears to be the case from other evidence. The spectra in Figs 8 and 9 show positive (upfield) shifts, when referred to $\mathrm{Et}_{3} \mathrm{P}\left[\delta 1.02\left(\mathrm{CH}_{3}\right), 1.36\left(\mathrm{CH}_{2}\right)\right.$, $\mathrm{CD}_{2} \mathrm{Cl}_{2}$ ] as the diamagnetic reference.

All known basket clusters are schematically depicted in Fig. 1. A recent addition to this set is $\mathrm{Fe}_{6} \mathrm{~S}_{5}\left(\mathrm{PBu}_{3}\right)_{4}(\mathrm{SPh})_{3}{ }^{33}(\mathrm{10})$, whose core structure is nearly identical to those of 7 and $\mathbf{8}$. This molecule differs from clusters 2-9 in the handle of the basket is thiolate- rather than sulphide-bridged; it is isoelectronic with 9 and, therefore, has a probable $S=1 / 2$ ground state. Cai et al. ${ }^{33}$ consider that the atoms $\mathrm{Fe}(2,4)$ are more reduced in $\mathbf{1 0}$ than in $\mathbf{6}$ because of $\mathrm{Fe}-\mathrm{S}$ distances in the handle which are $0.07 \AA$ longer than in the latter cluster. As yet, no Mössbauer or other spectroscopic and magnetic data have been reported that would permit a comparison of electronic features with those of clusters 2-9.

Acknowledgements-This research was supported by NIH Grant GM 28856 at Harvard University and by the Office of Naval Research program on Cluster Science and Dynamics under Contract No. N00014-89-J-1779 at MIT. The Francis Bitter National Laboratory is supported by the National Science Foundation.

\section{REFERENCES}

1. J. M. Berg and R. H. Holm, in Iron-Sulfur Proteins (Edited by T. G. Spiro), Ch. 1. Wiley-Interscience, New York (1982).

2. J.-F. You, B. S. Snyder, G. C. Papaefthymiou and R. H. Holm, J. Am. Chem. Soc. 1990, 112, 1067.

3. M. S. Reynolds and R. H. Holm, Inorg. Chem. 1988, 27, 4494. 
4. A. Agresti, M. Bacci, F. Cecconi, C. A. Ghilardi and S. Midollini, Inorg. Chem. 1985, 24, 689.

5. F. Cecconi, C. A. Ghilardi, S. Midollini, A. Orlandini and P. Zanello, J. Chem. Soc., Dalton Trans. 1987, 831.

6. V. Papefthymiou, M. Millar and E. Münck, Inorg. Chem. 1986, 25, 3010.

7. M. J. Carney, G. C. Papaefthymiou, M. A. Whitener, K. Spartalian, R. B. Frankel and R. H. Holm, Inorg. Chem. 1988, 27, 346.

8. M. J. Carney, G. C. Papaefthymiou, K. Spartalian, R. B. Frankel and R. H. Holm, J. Am. Chem. Soc. 1988, 110, 6084.

9. I. Noda, B. S. Snyder and R. H. Holm, Inorg. Chem. 1986, 25, 3851.

10. B. S. Snyder, M. S. Reynolds, I. Noda and R. H. Holm, Inorg. Chem. 1988, 27, 595.

11. B. S. Snyder and R. H. Holm, Inorg. Chem. 1988, 27, 2339.

12. B. S. Snyder and R. H. Holm, Inorg. Chem. 1990, 29, 274.

13. M. G. Kanatzidis, N. C. Baenziger, D. Coucouvanis, A. Simopoulos and A. Kostikas, J. Am. Chem. Soc. 1984, 106, 4500.

14. M. G. Kanatzidis, W. R. Hagen, W. R. Dunham, R. K. Lester and D. Coucouvanis, J. Am. Chem. Soc. $1985,107,953$.

15. M. G. Kanatzidis, A. Salifoglou and D. Coucouvanis, Inorg. Chem. 1986, 25, 2460.

16. D. Coucouvanis, M. G. Kanatzidis, A. Salifoglou, W. R. Dunham, A. Simopoulos, J. R. Sams, V. Papaefthymiou, A. Kostikas and C. E. Strouse, J. Am. Chem. Soc. 1987, 109, 6863.

17. C. J. O'Connor, Prog. Inorg. Chem. 1982, 29, 203.

18. D. H. Live and S. I. Chan, Anal. Chem. 1970, 42, 791.
19. W. Gerger, U. Mayer and V. Gutmann, Mh. Chem. 1977, 108, 417.

20. N. N. Greenwood and T. C. Gibb, Mössbauer Spectroscopy, Ch. 6. Chapman and Hall, London (1971).

21. T. Birchall, Can. J. Chem. 1969, 47, 1351.

22. S. Mitra, in Iron Porphyrins (Edited by A. B. P. Lever and H. B. Gray), Part 2, Ch. 1. Addison-Wesley, Reading, U.S.A. (1983).

23. V. R. Marathe and S. Mitra, J. Chem. Phys. 1983, 78,915 .

24. C. G. Barraclough, R. L. Martin, S. Mitra and R. C. Sherwood, J. Chem. Phys. 1970, 53, 1643.

25. P. D. W. Boyd, D. A. Buckingham, R. F. McMeeking and S. Mitra, Inorg. Chem. 1979, 18, 3585.

26. M. A. Bobrik, E. J. Laskowski, R. W. Johnson, W. O. Gillum, J. M. Berg, K. O. Hodgson and R. H. Holm, Inorg. Chem. 1978, 17, 1402.

27. M. J. Carney, J. A. Kovacs, Y. Zhang, G. C. Papaefthymiou, K. Spartalian, R. B. Frankel and R. H. Holm, Inorg. Chem. 1987, 26, 719.

28. R. B. Frankel, B. A. Averill and R. H. Holm, J. Phys. (Paris) 1974, 35, C6-107.

29. G. Christou, P. K. Mascharak, W. H. Armstrong, G. C. Papefthymiou, R. B. Frankel and R. H. Holm, J. Am. Chem. Soc. 1982, 104, 2820.

30. T. O'Sullivan and M. M. Millar, J. Am. Chem. Soc. 1985, 107, 4096.

31. M. A. Bobrik, K. O. Hodgson and R. H. Holm, Inorg. Chem. 1977, 16, 1851.

32. G. Lang and B. W. Dale, Nucl. Instrum. Meth. 1986, 108, 3541 .

33. J.-H. Cai, C.-N. Chen, Q.-T. Liu, B.-T. Zhuang, B.-S. Kang and J.-X. Lu, Jiegou Huaxue (J. Struct. Chem.) 1989, 8, 220. 